\title{
Síndrome de la bolsa de orina púrpura
}

\author{
Purple urine bag syndrome
}

\author{
Santiago Emilio Campbell, Arturo Izquierdo, Sebastián Campbell, \\ Lilia Erazo, Carlos Calderón • Florencia (Caquetá)
}

\section{Resumen}

Se presenta el caso de un paciente masculino de 62 años remitido por oncología para estudio por presentar orina de color morado. Desde hace tres meses tiene sonda vesical permanente por retención urinaria posterior a una resección quirúrgica de una metástasis cerebral por tumor primario a nivel pulmonar, tiene pendiente radioterapia holoencefálica y posterior quimioterapia sistémica. La única medicación que tomaba de manera intermitente era omeprazol, refería además anorexia y náuseas. La bolsa urinaria contenía orina de color morado y a la extracción aparecía turbia. El análisis de la orina fue compatible con infección urinaria. El color de la orina en la bolsa fue motivo de una interesante discusión científica. Se discuten los mecanismos a través de los cuales la orina toma dicho color (Acta Med Colomb 2011; 36: 38-40).

Palabras clave: bolsa urinaria, orina púrpura.

\begin{abstract}
The case is presented of a 62-year-old male patient who was referred by the Oncology Department for evaluation of purple-colored urine. Over the past three months the patient has had an indwelling catheter because of urinary retention after surgical resection of a brain metastasis of a lung tumor. The patient is to be treated with holoencephalic radiotherapy and afterwards with systemic chemotherapy. The only current medication was omeprazole, which he took intermittently. He also complained of anorexia and nausea. The urinary bag contained purple-colored urine, which appeared turbid upon extraction. Urinalysis was consistent with urinary tract infection. The color of the urine gave rise to an interesting scientific discussion. The mechanisms are discussed through which urine takes a purple color (Med Colomb 2011; 36: 38-40).
\end{abstract}

Keywords: urinary bag, purple urine.
Dr. Santiago Emilio Campbell Silva: Internista; Dr. Arturo Izquierdo: Cirujano; Dres. Sebastián Campbell Quintero, Lilia Erazo Guerrero y Carlos Calderón Torres: MD Urgencia. Clínica Mediláser-Florencia. Florencia (Caquetá).

Correspondencia. Dr. Santiago Campbell Silva, Calle 15 No. 12-34 Piso 2, Teléfono 098-4352673, Florencia, Caquetá

E-mail: santiago.campbell@gmail.com

Recibido: 05/II/2010 Aceptado: 29/XI/2010

\section{Introducción}

El síndrome de la bolsa de orina púrpura (the purple urine bag síndrome, $P U B S$ ) es una condición infrecuente que se ha observado principalmente en paciente de edad con sonda vesical para el drenaje urinario y se caracteriza por un color purpúrico intenso de la orina únicamente cuando el sistema colector es de plástico. El color es debido a una reacción química que involucra la orina, el plástico y ciertas enzimas de algunas bacterias. Se ha considerado que es una condición inofensiva para el paciente porque desaparece al tratar la infección urinaria (1). Describimos un caso típico de esta condición y del cual no encontramos informe en la literatura nacional. Esta circunstancia se convierte en una situación alarmante para el paciente, familiares y personal de salud, como sucedió con este caso. De ahí el interés de este raro e interesante fenómeno.

\section{Presentación del caso}

Se trata de un paciente de sexo masculino de 62 años de edad, docente pensionado y fumador hasta hace cuatro meses de dos cajetillas diarias de cigarrillo por 40 años y con antecedente de gastritis crónica diagnosticada por endoscopia digestiva. No se encontraron antecedentes farmacológicos y familiares de importancia. Por alteraciones de la marcha que se iniciaron hace cuatro meses y posterior pérdida del polígono de sustentación, hiporexia y malestar general, se le practicó una TAC de cráneo que mostró una lesión intraxial a nivel frontoparietal derecha con efecto de masa, edema vasogénico y evidencia de destrucción de la tabla ósea. Antes estos hechos se le practicaron en primera instancia biopsia y posterior resección. El informe de patología de la biopsia cerebral reportó un adenocarcinoma mal diferenciado con componentes de células claras metastásico, positivo para 
CD10, CK7, CK 20, P63 CDX CA 19-9. El tumor primario se ubicó a nivel pulmonar. Por presentar cuadro de retención urinaria posterior a la cirugía de resección se colocó sonda vesical que ha tenido de manera permanente por tres meses. Refirió además episodios de estreñimiento.

En el momento de la valoración se encontró a un paciente en regular estado general, consciente, orientado, con presión arterial de 125/83 $\mathrm{mmHg}$, frecuencia cardiaca de 78 / minuto, respiratoria de $18 /$ minuto y una temperatura de $37^{\circ} \mathrm{C}$. Peso de $72 \mathrm{~kg}$ y talla de $174 \mathrm{~cm}$. Al examen físico: cabeza y cuello sin ninguna alteración excepto área de cicatriz quirúrgica frontoparietal derecha; tórax con ruidos cardiacos rítmicos, sin soplo, galope o frote; campos pulmonares sin alteraciones; abdomen blando, depresible no doloroso y sin masas ni megalias; extremidades inferiores con edema asimétrico de pierna derecha; neurológico sin alteraciones significativas; genitourinario sonda vesical con presencia de orina de color violeta (Figuras 1, 2 y 3 ).

Los exámenes paraclínicos en ese momento reportaron: hemoglobina de $12.4 \mathrm{~g} / \mathrm{dL}$, hematocrito de $37 \mathrm{~g} / \mathrm{dL}$, leucocitos de 11800 con $79.1 \%$ de neutrófilos y $20.9 \%$ de linfocitos. Creatinina de $0.1 \mathrm{mg} / \mathrm{dL}$, BUN $16.7 \mathrm{mg} / \mathrm{dL}$, VSG de $38 \mathrm{~mm} / \mathrm{h}$, bilirrubina total 0.6 con directa de 0.1 $\mathrm{mg} / \mathrm{dL}$, AST $23 \mathrm{U} / \mathrm{L}$, ALT 12U/L y glucemia de $80 \mathrm{mg} / \mathrm{dL}$. El uroanálisis fue informado como orina de color turbio y olor fétido, $\mathrm{pH} 8.0$, proteínas $2+$, hematuria $1+$, nitritos positivos, bacterias $3+$, leucocitos 14-16xc. Urocultivo: Proteus mirabilis $>10^{4} \mathrm{ufc} / \mathrm{mL}$.

Con el cambio de la sonda vesical e inicio de la terapia con antibióticos no se volvió a observar dicha coloración.

\section{Discusión}

La utilización de catéteres vesicales para el drenaje urinario es una condición muy frecuente observada en la práctica médica en los diferentes hospitales y clínicas, así como en las diversas instituciones encargadas del cuidado de pacientes ancianos o por enfermedades crónicas, tanto en nuestro país como en el resto del mundo. No obstante, la observación de la coloración púrpura, violeta o morada de la bolsa que contiene la orina es muy rara y el informe de este hecho es inusual en la literatura, y en nuestro medio es desconocida su frecuencia. Los cambios en la coloración de la orina en la bolsa de drenaje pueden obedecer a diversas causas subyacentes fácilmente identificables en la gran mayoría de los casos, pero observar este color es realmente llamativo e infrecuente y se debe tener conocimiento de este raro fenómeno.

El síndrome de la bolsa de orina púrpura (PUBS por sus siglas en ingles) fue descrito por primera vez por Barlow and Dickson en 1978 (2). El contenido de la bolsa para la recolección de la orina puede tomar este color en horas o días después de colocada la sonda vesical, y el color puede ser más intenso entre más días transcurran entre el contacto de la orina con la bolsa, y no sólo compromete a la bolsa sino al catéter $(3,4)$. Investigaciones han revelado que este

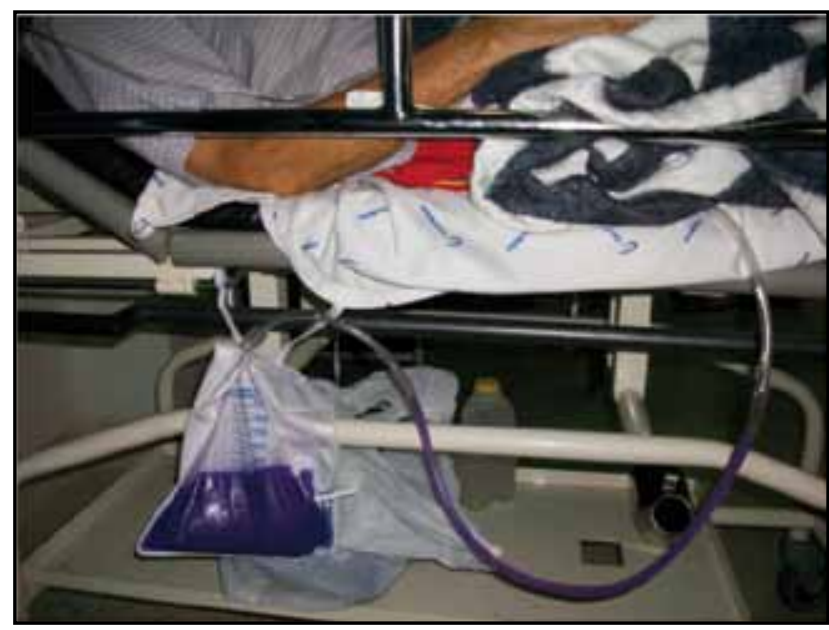

Figura 1. Orina púrpura en el tubo y en la bolsa urinaria con poca luminosidad. Se aprecia un color más oscuro.

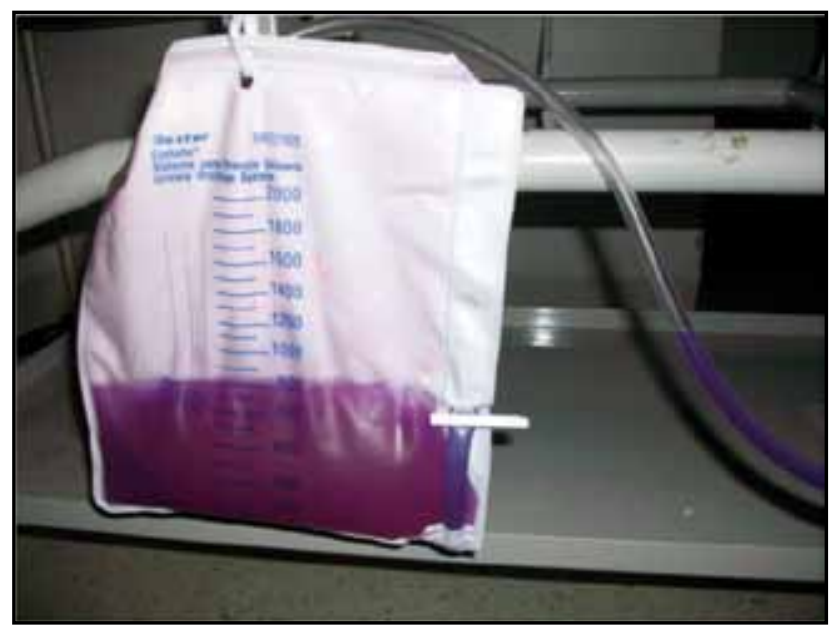

Figura 2. Aspecto de la orina con mayor luminosidad. En el tubo se aprecia más oscura.

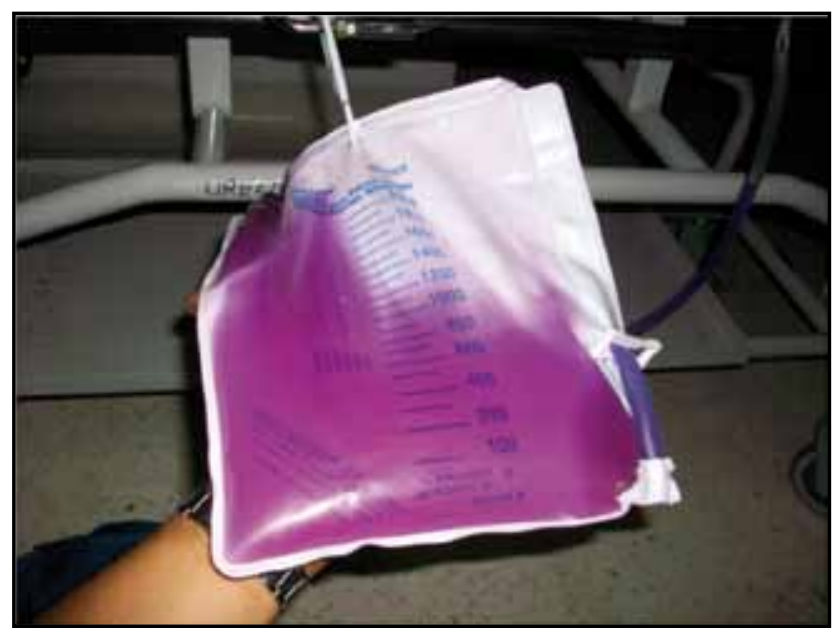

Figura 3. Aspecto de la orina bajo una fuente luminosa. 
síndrome es más frecuente en mujeres ancianas con daño cognitivo y el estreñimiento ha sido reportado como un síntoma frecuente en los pacientes con PUBS, lo mismo que la presencia de una orina alcalina y generalmente asociada a una infección urinaria (4-6).

La sonda vesical y la bolsa pueden cambiar de color de rojo o azul a púrpura y algunas veces pueden notarse los diferentes colores. La etiología de este síndrome es incierta pero se cree el índigo (azul) y la indirrubina (rojo) son los responsables del color observado. La reacción en cadena responsable para el PUBS comienza con el triptófano de los alimentos que es metabolizado a indol en el intestino, luego es absorbido, pasa a la circulación portal y convertido a sulfato de indoxyl en el hígado y excretado en la orina. Esta sustancia posteriormente es metabolizada a indoxyl por las enzimas sulfatasa/fosfatasa producidas por ciertas bacterias como Pseudomona aeruginosa, Proteus mirabilis, Morganela morganii, Escherichia coli, Klepsiella pneumoniae, Providentia stuartii, etc. El indoxyl en presencia de una orina alcalina, y de acuerdo a la concentración de oxígeno, cambia a índigo e indirrubina dando el color característico (3) (Figura 4).

Se ha sugerido que las sustancias químicas interactúan con el material plástico de la bolsa y de la sonda vesical fabricados con cloruro de polivinilo (PVC) formando una capa de recubrimiento (3). Es interesante observar que la orina no es púrpura al ser colocada en otro recipiente estéril. El PUBS, aunque ha sido considerado una condición benigna, es un hecho alarmante, y según algunos autores, no necesita un tratamiento agresivo con antibióticos, y se resuelve con un buen manejo de la sonda vesical como puede ser el reemplazo prudencial (7); mientras que otros investigadores no lo consideran así y alertan sobre esta rara ocurrencia (8).

En resumen, presentamos a un paciente de sexo masculino no hospitalizado que reúne las condiciones para la presentación de este raro fenómeno que fue resuelto con el cambio de la sonda vesical y el tratamiento para la infección urinaria. Hasta el momento no ha vuelto a presentar dicha condición.

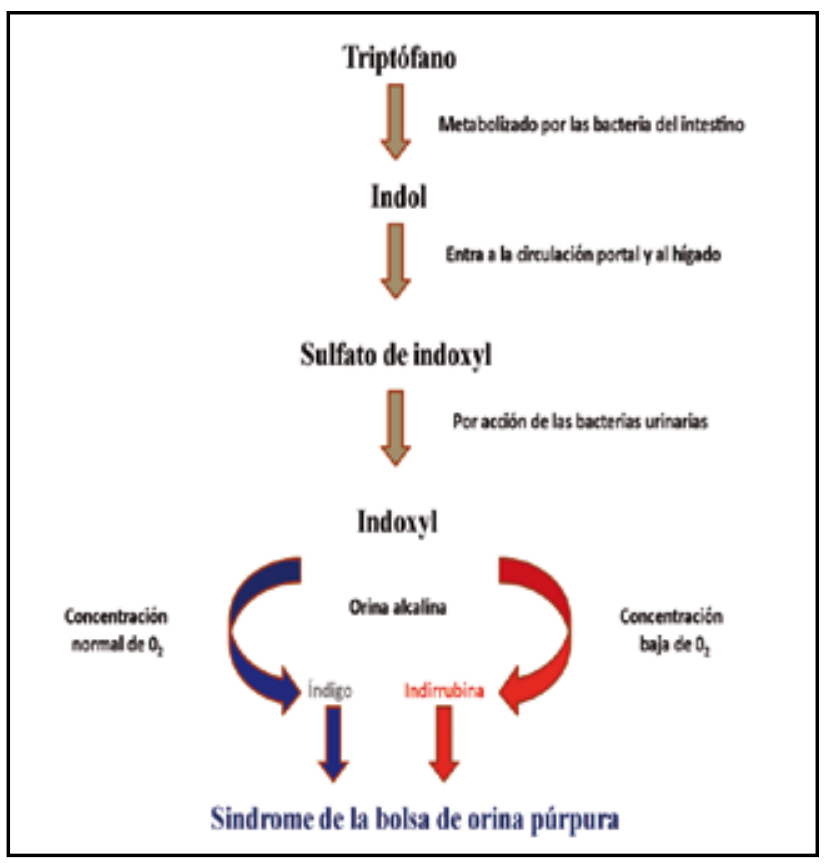

Figura 4. Vía propuesta del triptófano en el síndrome de la bolsa de orina púrpura (7).

\section{Referencias}

1. Beunk J, Lambert M, Mets T. The purple urine bag syndrome. Age and Ageing 2006; 35: 542.

2. Barlow GB, Dickson JAS. Purple urine bags. Lancet 1978; 1: 220-1.

3. Su FH, Chung SY, Chen MH, Sheng ML, Chen CH, Chen YJ, et al. Case analysis of purple urine-bag syndrome at a long-term care service in a community hospital. Chang Gung Med J 2005; 28: 636-42.

4. Harun NS, Nainar SK, Chong VH. Purple urine bag syndrome: a rare and interesting phenomenon. South Med J 2007; 100:1048-50.

5. Tan CK, Wu YP, Wu HY, Lai CC. Purple urine bag syndrome. Can Med Assoc J 2008; 179: 491.

6. Yamazaki Y, Kobatake K. The purple urine bag syndrome. BMJ Case Reports 2009.

7. Hussain AS, Haroon D, MB. The purple urine bag syndrome. Amjmed Case Reports 2009

8. Tasi YM, Huang MS, Yang CJ, Yeh SM, Liu CC. Purple urine bag syndrome, not always a benign process. Am J Emerg Med 2009; 7: 895-7. 